\title{
Inversion of Marine Gravity Anomalies over Southeastern China Seas from Multi-satellite Altimeter Vertical Deflections
}

\author{
Shengjun Zhang ${ }^{1}$ David T.Sandwell ${ }^{2}$ Taoyong Jin ${ }^{1,3^{*}}$ Dawei $\mathrm{Li}^{1,3}$ \\ 1 School of Geodesy and Geomatic, Wuhan University, Wuhan, China \\ 2 Scripps Institution of Oceanography, La Jolla, CA, United States \\ 3 Key Laboratory of Geospace Environment and Geodesy, Ministry of Education, Wuhan, \\ China
}

Abstract: The accuracy and resolution of marine gravity field derived from satellite altimetry mainly depends on the range precision and dense spatial distribution. This paper aims at modeling a regional marine gravity field with improved accuracy and higher resolution $\left(1^{\prime} \times 1^{\prime}\right)$ over Southeastern China Seas using additional data from CryoSat-2 as well as new data from AltiKa. Three approaches are used to enhance the precision level of satellite-derived gravity anomalies. Firstly we evaluate a suite of published retracking algorithms and find the two-step retracker is optimal for open ocean waveforms. Secondly, we evaluate the filtering and resampling procedure used to reduce the full 20 or $40 \mathrm{~Hz}$ data to a lower rate having lower noise. We adopt a uniform low-pass filter for all altimeter missions and resample at $5 \mathrm{~Hz}$ and then perform a second editing based on sea surface slope estimates from previous models. Thirdly, we selected WHU12 model to update the corrections provided in geophysical data record. We finally calculated the $1^{\prime} \times 1^{\prime}$ marine gravity field model by using EGM2008 model as reference field during the remove/restore procedure. The root mean squares of the discrepancies between the new result and DTU10, DTU13, V23.1, EGM2008 are within the range of $1.8 \sim 3.9 \mathrm{mGal}$, while the verification with respect to shipboard gravity data shows that the accuracy of the new result reached a comparable level with DTU13 and was slightly superior to V23.1, DTU10 and EGM2008 models. Moreover, the new result has a $2 \mathrm{mGal}$ better accuracy over open seas than coastal areas with shallow water depth.

Keywords: satellite altimetry; waveform retracking; vertical deflection; gravity anomaly 


\section{Introduction}

Marine gravity anomalies are important data sources to construct Earth's gravity model and investigate global tectonics and continental margin structure, which can be derived from radar altimeter measurements of ocean surface height (Rapp, 1979; Haxby et al., 1983) or slope (Sandwell and Smith, 1997; Andersen and Knudsen, 1998; Hwang et al., 1998). The development of marine gravity field model mainly relies on the accuracy and resolution of accumulated multi-satellite altimeter data. The Southeastern China Seas, especially the South China Sea, have relatively complex seafloor topography, and these areas are both attractive for oceanographers and geodetic scientists. Over the past two decades, several regional marine gravity models over Southeastern China Seas have been constructed from satellite altimetry data (HSU et al., 1999; Li et al., 2001; Huang et al., 2001\&2006; Yang et al., 2008). However, the optimal resolution of inversed models was $2^{\prime} \times 2^{\prime}$, which is lower than the resolution of latest global mainstream models $\left(1^{\prime} \times 1^{\prime}\right)$ such as DTU13 (Andersen et al., 2014) and V23.1 (Sandwell et al., 2014). Moreover, these global models are not always optimal in coastal areas and complex regions with islands as it is well known that the quality of satellite-derived gravity data degrades close to the coast.

The quality of marine gravity field model derived from satellite altimeter is manifested on two aspects as accuracy and resolution, which mainly depends on the following factors: (1) the altimeter range precision (2) the spatial track density and along-track sampling rate (3) the diverse track orientation (4) the accuracy of modeled ocean tide corrections, especially over the coastal areas and (5) the low-pass filters applied to the profile data. The accuracy of altimeter observations can be improved through waveform retracking and careful low-pass filtering. Moreover, the requirement for density and diversity can be satisfied through along-track resampling and new data supplement with geodetic mission or different orbital parameters.

In recent years, the algorithms for retracking altimeter waveforms have gone through considerable development (Garcia et al., 2014), which provides great opportunity for improving the precision of existing altimeter data. Meanwhile, CryoSat-2 has accumulated large amount of observations for several complete 369d cycles with different track 
orientations. Jason-1 implemented geodetic mission (GM) for almost a complete $406.5 \mathrm{~d}$ period at the end of its operation stage as planed. Both the missions achieved the goal of dense spatial track, while the corresponding range precision is superior over the data of previous geodetic missions, such as Geosat and ERS-1. In addition, the measurements of SARAL/AltiKa have better range precision and higher resolution by increasing the operating frequency, pulse repetition frequency, bandwidth and reducing the beamwidth of the antenna pattern (Raney et al., 2011; Zhang and Sandwell, 2016). Combined with the existing altimeter data set, the new supplements of CryoSat-2, Jason-1 GM and SARAL/AltiKa in recent years provide a great opportunity of modeling improved marine gravity field due to their diversified spatial track distribution and enhanced range precision (Smith, 2015; Zhang and Sandwell, 2016).

Therefore, this paper addresses the following questions over the Southeastern China Seas $\left(100^{\circ} \sim 140^{\circ} \mathrm{E}, 0^{\circ} \sim 40^{\circ} \mathrm{N}\right)$ : (1) Which retracker is optimal for range precision over the open ocean? (2) Which tidal model is more reliable? (3) Can one adjust processing and editing parameters to construct a regional marine gravity field with better accuracy and higher resolution than previous solutions? Eight high-precision radar altimeter missions (Geosat 1985-1989, ERS-1 1991-1998, T/P 1992-2006, ERS-2 1995-2011, Jason-1 2001-2013, Envisat 2002-2012, CryoSat-2 2010-present, SARAL/AltiKa 2013-present) have accumulated large amount of sea surface height (SSH) measurements. Based on the available altimeter data mentioned above, a new regional gravity model with 1 ' $\times 1$ ' resolution will be constructed and validated in the research area.

\section{Retracker selection}

A satellite altimeter measures the range to the land, ice, or ocean surface by emitting a series of frequency-modulated chirp signals designed to act like brief Gaussian-shaped radar pulses. These pulses interact with the surface and the received power of the reflected signal is recorded by the satellite altimeter over a short observation window equivalent to $\sim 60 \mathrm{~m}$ of range. Averages of the power received from many echoes are referred to as altimeter waveforms. The leading edge of the waveform is crudely tracked onboard the satellite to keep 
the return pulse near the center of the window. The leading edge can be estimated more accurately (i.e. retracked) in post processing. A variety of waveform retracking algorithms have been proposed and the optimal algorithm depends on the slope and roughness of the reflective surface (land, ice, or ocean). The models can be purely empirical or based on physics (Sarrailh et al., 1997; Gommenginger et al., 2011). Here we evaluate a number of retracking algorithms to compare their performance over open ocean surfaces. We expect the retrackers that are optimized for land or ice will perform poorly over the ocean and our analysis confirms that expectation and provides an objective basis for the selection of the optimal retracker. Nevertheless we use these suboptimal retrackers to provide a first estimate of the leading edge of the waveform to improve the convergence of the numerically slower Brown-model type retrackers (Brown, 1977).

We begin with retrackers that are optimized for ice and land surfaces, which are commonly rough and can have significant slope within the beamwidth of the radar footprint. The offset center of gravity (OCOG) algorithm was developed by Wingham et al. (1986) to achieve robust retracking and its goal is to find the center of gravity for each waveform based on the power levels within the gates. The threshold retracker was developed by Davis (1993) and this algorithm uses a prescribed threshold value with respect to the OCOG amplitude or the maximum waveform amplitude to determine the objective gate and improve the estimation of range. The improved threshold retracker has been developed in the case of complex waveforms to identify sub-waveforms within the measured waveform and select the best ranging gate (Hwang et al., 2006; Chang et al., 2006; Guo et al., 2010). The Beta-5 parameter retracker was developed by Martin et al. (1983) to retrieve ranges from the single-ramp return waveforms by fitting a 5-parameter functional model. These purely empirical retrackers perform well over surfaces where the shape of the return waveform is highly variable.

Over the open ocean the waveform shape is well approximated by a Brown-type model (Brown, 1977) which consists of a sharp error-function step in power with a more gradual decay in the trailing edge due to the finite beam width of the projected antenna pattern (Brown, 1977; Amarouche et al., 2004). For example, the maximum likelihood estimator (MLE) is a statistical retracking method to fit the theoretical Brown model return power to the 


\begin{tabular}{|c|c|c|c|c|c|c|c|}
\hline & MLE & OCOG & Threshold & $\begin{array}{l}\text { Improved } \\
\text { Threshold }\end{array}$ & Beta-5 & WLS-1 $1^{\text {st }}$-step & WLS-2 $2^{\text {nd }}$-step \\
\hline MLE & 1 & 0.646 & 0.978 & 0.938 & 0.980 & 0.951 & 0.961 \\
\hline OCOG & & 1 & 0.656 & 0.622 & 0.641 & 0.667 & 0.640 \\
\hline Threshold & & & 1 & 0.959 & 0.962 & 0.945 & 0.967 \\
\hline $\begin{array}{l}\text { Improved } \\
\text { threshold }\end{array}$ & & & & 1 & 0.923 & 0.914 & 0.928 \\
\hline Beta-5 & & & & & 1 & 0.934 & 0.944 \\
\hline WLS-1 ${ }^{\text {st }}$-step & & & & & & 1 & 0.963 \\
\hline WLS-2 ${ }^{\text {nd }}$-step & & & & & & & 1 \\
\hline
\end{tabular}

measured return power (Challenor and Scrokosz, 1989). This algorithm can use a 4-parameter Brown-type model to estimate arrival time, rise time, waveform amplitude and the rate of the decay of the trailing edge of the waveform and it is called MLE4. The MLE4 retracker is used to generate the standard product in the sensor geophysical data records (SGDR) of Jason-1. A modification of this algorithm was proposed by (Sandwell and Smith, 2005) to decouple the correlation between arrival time and significant wave height that occurs in the MLE4 algorithm. The decoupling is achieved by first performing a 3-parameter retracking assuming a constant trailing edge decay; we'll call this WLS-1 ${ }^{\text {st }}$-step. Then the parameter representing the rise time (i.e. significant wave height or SWH) of the leading edge is smoothed over a $1 \frac{1}{2}$ wavelength of $45 \mathrm{~km}$. A second retracking is performed using this smoothed rise time as a known parameter so the second-pass has only two parameters. This two-step approach has proved effective for most of the conventional radar altimeters (Garcia et al., 2014).

Two approaches were used to select the optimal retracking algorithm for recovery of the ocean surface height and slope. We evaluate all the retrackers using the 501st cycle of Jason-1 GM data. First we perform a regression between the arrival time of each pair of the 7 retrackers discussed above and calculate the correlation coefficient. The results are provided in Table 1. In general the arrival times from all the retrackers except the OCOG are highly correlated $(>0.91)$. The 2 -step, weighted least squares retracker (WLS- $2^{\text {nd }}$ ) shows the best correlation with all the other retrackers suggesting it is optimal. 

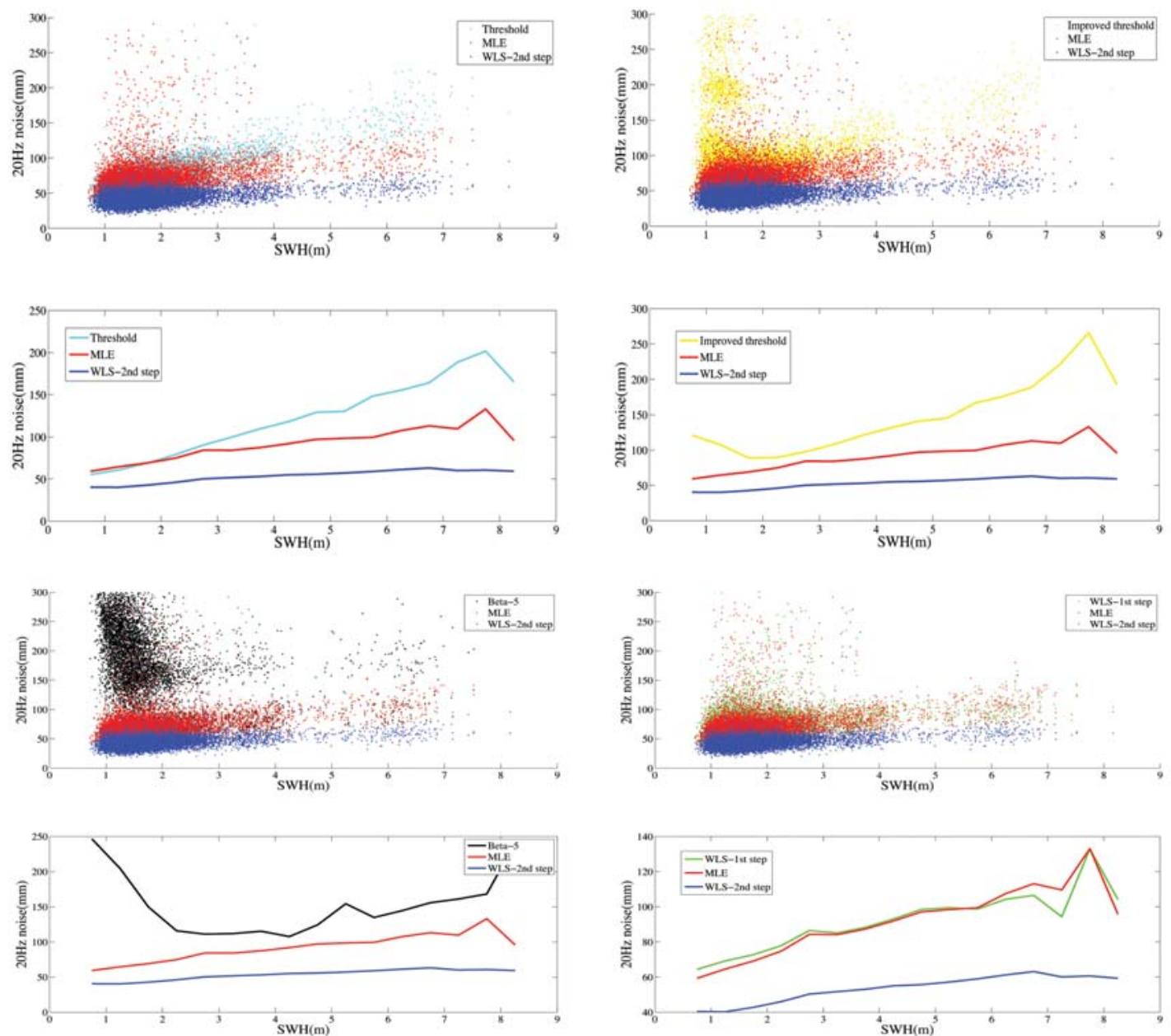

Figure.1 Statistics of along-track standard deviation for different retracking methods

(Threshold - cyan; MLE provided in SGDR - red; WLS-2 ${ }^{\text {nd }}$ step - blue Improved threshold - yellow; Beta-5 - black; WLS-1 ${ }^{\text {st }}$ step - green)

Second evaluation approach is to calculate the standard deviation of the $20 \mathrm{~Hz}$ range correction in 1 second bins for each of the 6 best retrackers (OCOG was not evaluated). After removal of the range from the EGM2008 model, the range correction should be constant over this short interval. These standard deviations should increase with increasing SWH as shown in Figure 1. This process was repeated for retracked results of threshold (cyan dots), improved threshold (yellow dots), Beta-5 (black dots) and WLS-1 ${ }^{\text {st }}$ step (green dots) algorithms in contrast with results of WLS-2 ${ }^{\text {nd }}$ step (blue dots) and MLE (red dots) methods. The smoothed curves in Figure 1 represent the average values of statistical standard deviations corresponding to the $0.5 \mathrm{~m}$ bins of SWH. The lowest value of the standard deviations derived from WLS $-2^{\text {nd }}$ step retracker (blue dots and blue line) means the minimum noise level comparing with other retracking algorithms, which proves the advantage of the two-step WLS 
retracker for constraining noise level and recovering optimal gravity field. Besides, this two-step WLS retracker is suitable for all the conventional altimeter data and brings obvious improvements in range precision (Sandwell and Smith, 2005\&2009; Garcia et al., 2014; Zhang and Sandwell, 2016). Therefore, the two-step WLS retracker is selected for waveforms of different altimeter missions to construct gravity field model in this paper.

\section{Gravity field model construction}

The main objective of our analysis is to construct a grid of marine gravity anomalies from satellite altimeter profiles of ocean surface height. The ocean surface is a close approximation to the geoid height (gravitational potential) and the gravity anomaly is the vertical derivative of the geoid. Since we are not interested in constructing the geoid, we perform the derivative directly on the raw altimeter profiles. These along-track slopes are combined in a biharmonic spline analysis to construct east and north grids of sea surface slope and then into gravity anomalies using Laplace's equation (e.g., Sandwell, 1984; Hwang, 1998; Sandwell and Smith, 2009). As discussed in Olgiati et al. (1995) there are significant computational and accuracy benefits to constructing gravity from along-track slopes rather than first constructing a geoid model and then differentiating to obtain gravity. Moreover, factors that affect the absolute height accuracy of altimetric sea level such as radial orbit error, ionosphere/troposphere delays and deep ocean tides (Chelton et al. 2001) have correlation scales long enough that they yield negligible error in along-track slope (Sandwell and Smith 2009). The conversion of vertical deflections to gravity anomalies is a boundary-value problem for Laplace's equation (Sandwell and Smith, 1997). The most accurate computations use spherical harmonics at long wavelengths, supplemented by Fourier transforms on data projected onto a flat plane for short wavelengths (Sandwell and Smith, 2009). This method meets the requirement of gravity field accuracy and omits the construction of complex kernel function at the same time. As a result, we follow this standard practice in geodesy known as "remove-restore" to construct the regional marine gravity model and the referred gravity model is EGM2008 in this paper.

We use all available altimeter data including: Geosat GM\&ERM, ERS-1 GM\&ERM, T/P, Envisat and Jason-1 ERM, CryoSat-2, Jason-1 GM and SARAL/AltiKa data to construct the 
regional marine gravity field model. Data distribution of multi-satellite altimeters over the Southeastern China Seas is shown in Figure 2.
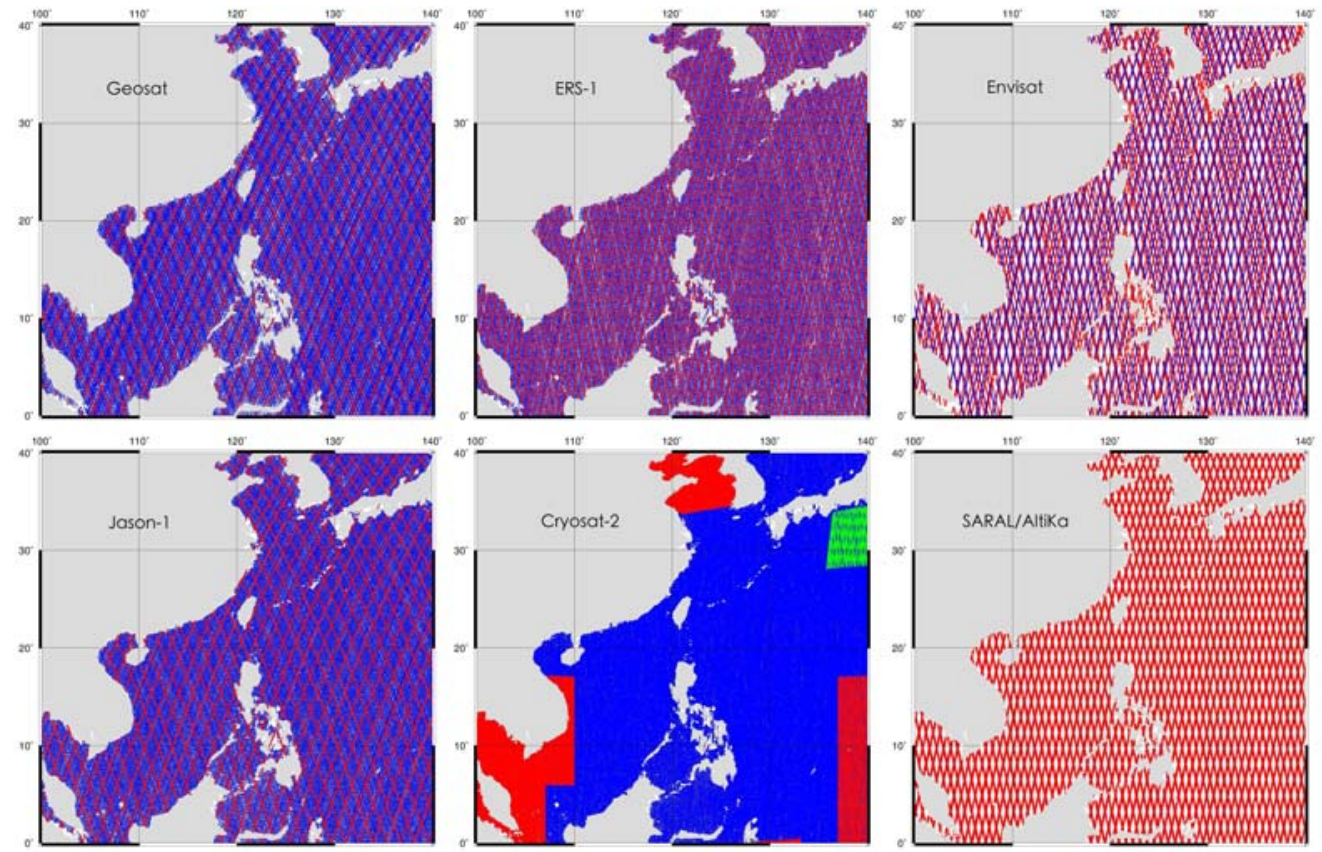

Figure. 2 Distribution of multi-satellite altimeter data in the research area

The Geosat, ERS-1 and Jason-1 data can all be divided into two categories - exact repetitive mission (red spots in Figure 2) and geodetic mission (blue spots in Figure 2) respectively. The T/P data has same distribution comparing to Jason-1 ERM data and the corresponding subfigure for Jaosn-1 does not distinguish them accordingly. In addition, Envisat does not include geodetic phase but have two phases of exact repetitive mission with different periods of 35d (red spots in Figure 2) and 30d (blue spots in Figure 2) separately. Moreover, CryoSat-2 has three measurement modes including the low-resolution mode (LRM, blue spots in Figure 2), the synthetic aperture mode (SAR, red spots in Figure 2) and the synthetic aperture interferometer mode (SIN, green spots in Figure 2).

\begin{tabular}{cccccccccc}
\multicolumn{8}{c}{ Table.2 Parameters for Sandwell retracking method for multi-satellites altimeter data } \\
\hline \multirow{2}{*}{ Satellite mission } & \multirow{2}{*}{ Geosat } & ERS-1 & Envisat & $\begin{array}{c}\text { T/P } \\
\text { Jason-1 }\end{array}$ & $\begin{array}{c}\text { CryoSat-2 } \\
\text { LRM }\end{array}$ & $\begin{array}{c}\text { CryoSat-2 } \\
\text { SAR }\end{array}$ & $\begin{array}{c}\text { CryoSat-2 } \\
\text { SIN }\end{array}$ & $\begin{array}{c}\text { SARAL/ } \\
\text { AltiKa }\end{array}$ \\
\hline$\alpha$ & 0.006 & 0.022 & 0.09 & 0.0058 & 0.013 & 0.00744 & 0.00744 & 0.0351 \\
gate spacing/mm & 468.257 & 454.067 & 468.257 & 468.257 & 428.12 & 428.12 & 428.12 & 312.284 \\
\hline
\end{tabular}

Note that $\alpha$ is the best trailing edge decay parameter in units of gates ${ }^{-1}$.

Based on the previous analysis in section 2, the two-step WLS retracker was selected for retracking raw waveforms of various altimeter missions except CryoSat-2 SAR and SIN data 
which do not benefit from two-step retracking (Garcia et al., 2014). The corresponding parameters for different missions are provided in Table 2 and the fitting results for typical waveforms of Cryosat-2, Jason-1, Envisat and SARAL/AltiKa are shown in Figure 3, demonstrating that the chosen parameters obtained reliable agreement between sample power values and the fitting modeled power values.
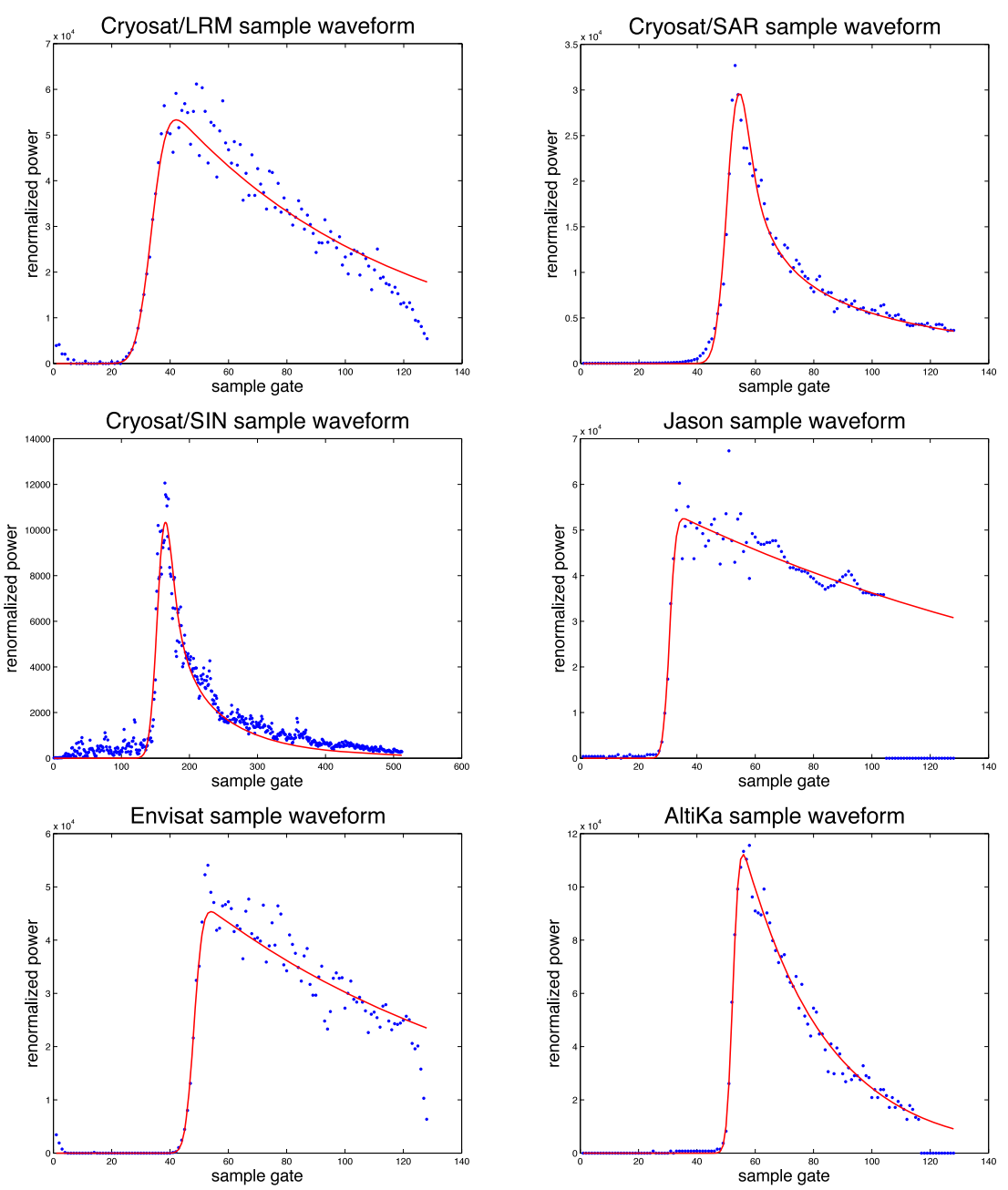

Figure.3 Fitting results of typical waveforms using two-step WLS retracker for Cryosat-2, Jason-1, Envisat and SARAL/AltiKa. Note the CryoSat-2 SAR and SIN waveforms were retracked using a SAR waveform model

(Garcia et al., 2014).

To assess the noise level of retracked data, we performed the statistical analysis of along-track standard deviations again as previously mentioned in section 2. Under the typical condition of $2 \mathrm{~m}$ and $6 \mathrm{~m} \mathrm{SWH}$, mean values of standard deviations in $0.5 \mathrm{~m}$ SWH bins are listed in Table 3(Garcia et al., 2014). The results demonstrate that the noise level of $2^{\text {nd }}$ step retracked data by WLS estimator is significantly lower than the $1^{\text {st }}$ step retracked results for most of satellite missions except CryoSat-2 SAR and SIN. The SAR and SIN mode data do 
213

not benefit from the $2^{\text {nd }}$ step of WLS retracker as the arrival time and SWH are not strongly correlated during the least squared fitting process due to the more complex shape of waveforms. Moreover, the major difference between $2^{\text {nd }}$ step result and $1^{\text {st }}$ step result is that the former procedure adopts along-track smoothed SWH as priori information rather than a parameter to be solved, which brings significantly improvement over the accuracy level as a factor of 1.5. It is remarkable that the retracked Ka-band data of SARAL/AltiKa has an obviously lower noise level compared to most of Ku-band retracked results. The precision dominance of Ka-band data is also mentioned by several publications (Raney et al., 2011; Smith, 2015).

Table.3 Along-track standard deviation for retracked altimeter data under sea state conditions of $2 \mathrm{~m}$ (typical) and

\begin{tabular}{ccccc}
\multicolumn{5}{c}{ 6m Unit: $\mathrm{mm}$} \\
\hline Satellite mission & $1^{\text {st }}$ step@ $2 \mathrm{~m}$ & $2^{\text {nd }}$ step $@ 2 \mathrm{~m}$ & $1^{\text {st }}$ step/2 ${ }^{\text {nd }}$ step@ $2 \mathrm{~m}$ & $2^{\text {nd }}$ step@6m \\
\hline Geosat & 88.0 & 57.0 & 1.54 & 105.4 \\
ERS-1 & 93.6 & 61.8 & 1.51 & 111.8 \\
Envisat & 78.9 & 51.8 & 1.52 & 88.6 \\
Jason-1 & 75.9 & 46.4 & 1.63 & 64.2 \\
CryoSat-2/LRM & 64.7 & 42.7 & 1.51 & 71.7 \\
CryoSat-2/SAR & 49.5 & 49.7 & 0.996 & 110.9 \\
CryoSat-2/SIN & 138.5 & 138.7 & 0.998 & 148.6 \\
SARAL/AltiKa & 45.8 & 26.3 & 1.74 & 46.2 \\
\hline
\end{tabular}
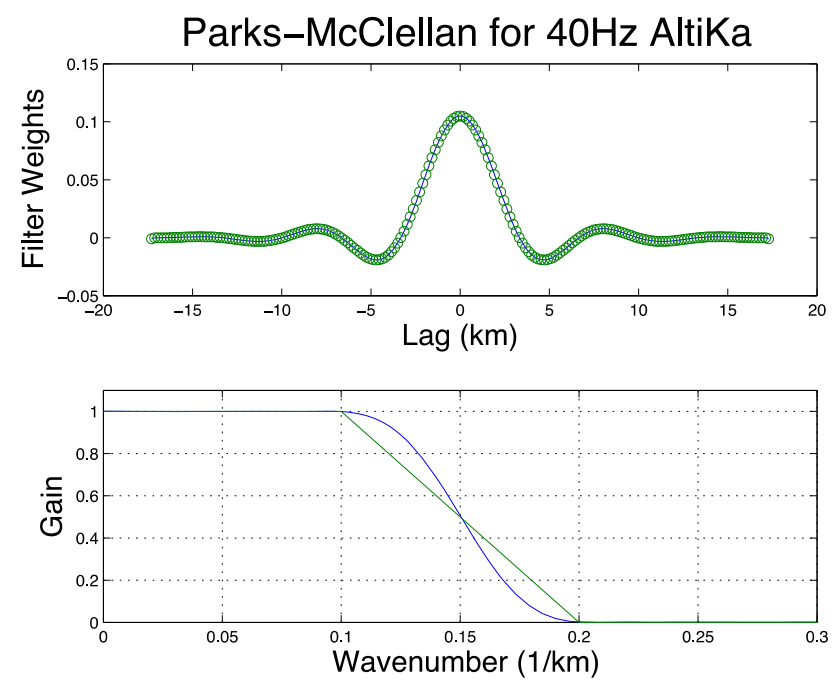

Figure.4 Low-pass filter designed for SARAL/AltiKa and its impulse response in space domain 
before computing the along-track sea surface slope. Prior do downsampling we apply a low-pass filter with a 0.5 gain at a wavelength of $6.7 \mathrm{~km}$. For each satellite, the filter was 231 designed in Matlab using the Parks-McClellan algorithm. Taking SARAL/AltiKa for example, the filter rolls off nearly linearly over a band from $10 \mathrm{~km}$ to $5 \mathrm{~km}$ (Figure 4 lower). The detailed impulse response for the filter is shown in Figure 4. Besides, The corresponding low-pass filters designed for different missions are plotted for a comparison in Figure 5 according to their time-space intervals listed in Table 4. The lengths of along-track data series involved in the low-pass filter are 49, 99, 99 and 199, corresponding to along-track measurements with highest available data rate of $10 \mathrm{~Hz}, 18 \mathrm{~Hz}, 20 \mathrm{~Hz}$ and $40 \mathrm{~Hz}$, respectively.

\begin{tabular}{cccccc}
\multicolumn{6}{c}{ Table.4 Time-space interval before and after the resampling process for multi-satellite altimeters } \\
\hline Satellite missions & velocity $(\mathrm{m} / \mathrm{s})$ & $\mathrm{dt} 1(\mathrm{~s})$ & $\mathrm{dt} 2(\mathrm{~s}) / 5 \mathrm{~Hz}$ & $\mathrm{dx} 1(\mathrm{~m})$ & $\mathrm{dx} 2(\mathrm{~m}) / 5 \mathrm{~Hz}$ \\
\hline Geosat & 6770 & 0.098 & 0.196 & $663.5(10 \mathrm{~Hz})$ & 1326.9 \\
ERS-1 & 6690 & 0.049 & 0.196 & 327.9 & 1312.0 \\
Envisat & 6690 & 0.055 & 0.222 & $372.6(18 \mathrm{~Hz})$ & 1490.5 \\
Jason-1 & 5740 & 0.051 & 0.204 & 292.6 & 1170.4 \\
CryoSat-2/LRM & 6779 & 0.047 & 0.188 & 319.8 & 1279.2 \\
CryoSat-2/SAR & 6779 & 0.044 & 0.176 & 299.8 & 1197.3 \\
CryoSat-2/SIN & 6779 & 0.044 & 0.176 & 299.3 & 1193.8 \\
SARAL/AltiKa & 6690 & 0.026 & 0.209 & $174.7(40 \mathrm{~Hz})$ & 1397.9 \\
\hline
\end{tabular}

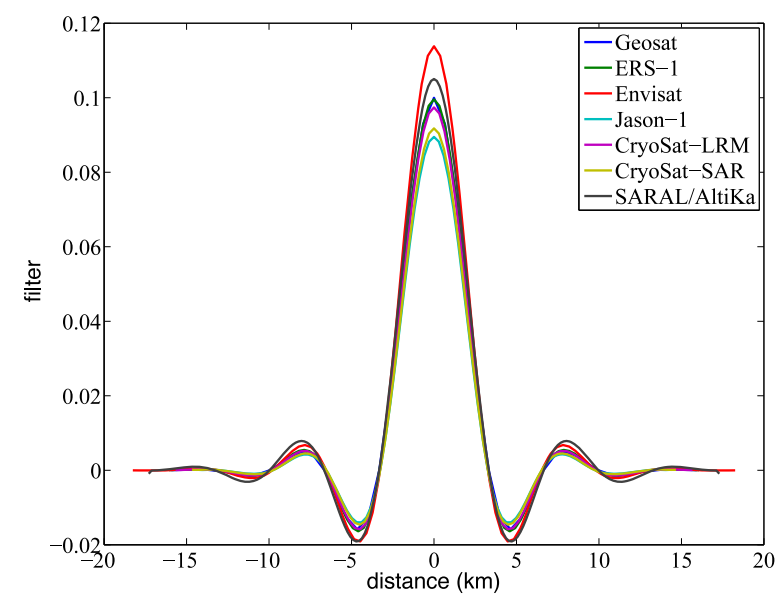

Figure.5 Low-pass filters used in the resampling procedure for multi-satellite altimeters

On the basis of processed range observations after waveform retracking and resampling, the $\mathrm{SSH}$ are computed for along-track $5 \mathrm{~Hz}$ sampling rate by considering corresponding corrections for path delay and geophysical environment effects. Among them, the ocean tide model errors are the major error sources for calculating sea surface height slopes (Sandwell and Smith, 2009). Therefore, all the corrections for path delay and geophysical environment 
246 are considered using items supplied by level 2 products during this procedure except the 247 ocean tide.

248 Table.5 Discrepancy value of 4 main components of ocean tide with respect to 137 tide gauges data Unit: $\mathrm{cm}$

\begin{tabular}{ccccc}
\hline Tide model & M2 & S2 & K1 & O1 \\
\hline FES2004 & 28.99 & 14.86 & 5.38 & 4.14 \\
GOT4.7 & 24.75 & 13.20 & 3.26 & 4.26 \\
EOT10a & 28.50 & 15.20 & 4.70 & 3.57 \\
DTU10 & 21.22 & 12.08 & 3.97 & 3.19 \\
WHU12 & 17.88 & 11.03 & 3.62 & 2.72 \\
\hline
\end{tabular}

The GOT4.7 model is the result of an empirical harmonic analysis of satellite altimetry relative to an adopted prior model, and follows the long series of similar efforts starting with 251 Schrama and Ray (1994). FES2004 is one version of a series of finite element solutions tidal atlases, computed from tidal hydrodynamic equations and data assimilation (Lyard et al., 2006). The DTU10 model is based on an empirical correction to the FES2004, in which the largest residual tides were determined using the response method (Cheng and Andersen, 2011). EOT10a is a global solution for harmonic constants of the most dominant ocean tide constituents, derived by means of empirical analysis for multi-mission satellite altimetry data (Savcenko and Bosch, 2008). The recently published WHU12 is an empirical ocean tide model determined directly using an orthogonal representation of the response analysis without a background ocean tide model as a priori model. Comparing with 137 tide gauges data, the verification for 4 main components of ocean tide show that the WHU12 model has reliable accuracy level over China coastal areas as listed in Table 5. It is a reliable way to evaluate the accuracy of different models based on a comprehensive tide gauge data sets for tidal constituents (Stammer et al., 2014). As a result, we uniformly adopt WHU12 model to calculate the ocean tidal corrections for uniformly along-track $5 \mathrm{~Hz}$ measurement of different satellite missions.

After that, the along-track sea surface height gradients are computed, while along-track gradient of EGM2008 model are also interpolated for a preliminary verification. Our edit threshold of discrepancy between the two gradients was set at three times the standard 269 deviation given in Table 6. This prior model furnishes a sanity check that allows us to detect 270 outliers that produce spurious slopes. The corresponding proportions of eliminated data are 271 also provided in Table 6. Considering that the high frequency noise is amplified during the 
272 process of difference, we used a second low-pass filter according to the principle of a 0.5 gain 273 at $10 \mathrm{~km}$ wavelength. The designed Parks-McClellan filters for various missions are shown in $274 \quad$ Figure 6 and the lengths are uniformly set to be 30 .

275 Table.6 Threshold for editing gross errors for multi-satellite altimeter along-track slopes Unit: $\mathrm{m} / \mathrm{s}$

\begin{tabular}{|c|c|c|c|c|c|c|c|c|c|}
\hline $\begin{array}{l}\text { Satellite } \\
\text { Missions }\end{array}$ & Geosat & ERS-1 & Envisat & $\mathrm{T} / \mathrm{P}$ & Jason-1 & $\begin{array}{c}\text { CryoSat-2 } \\
\text { LRM }\end{array}$ & $\begin{array}{c}\text { CryoSat-2 } \\
\text { SAR }\end{array}$ & $\begin{array}{c}\text { CryoSat-2 } \\
\text { SIN }\end{array}$ & $\begin{array}{l}\text { SARAL/ } \\
\text { AltiKa }\end{array}$ \\
\hline Threshold & 25 & 30 & 33 & 20 & 28 & 31 & 35 & 48 & 30 \\
\hline $\begin{array}{c}\text { Delete } \\
\text { Percentage }\end{array}$ & $1.36 \%$ & $1.54 \%$ & $0.86 \%$ & $1.85 \%$ & $1.10 \%$ & $0.96 \%$ & $2.21 \%$ & $0.64 \%$ & $1.10 \%$ \\
\hline
\end{tabular}

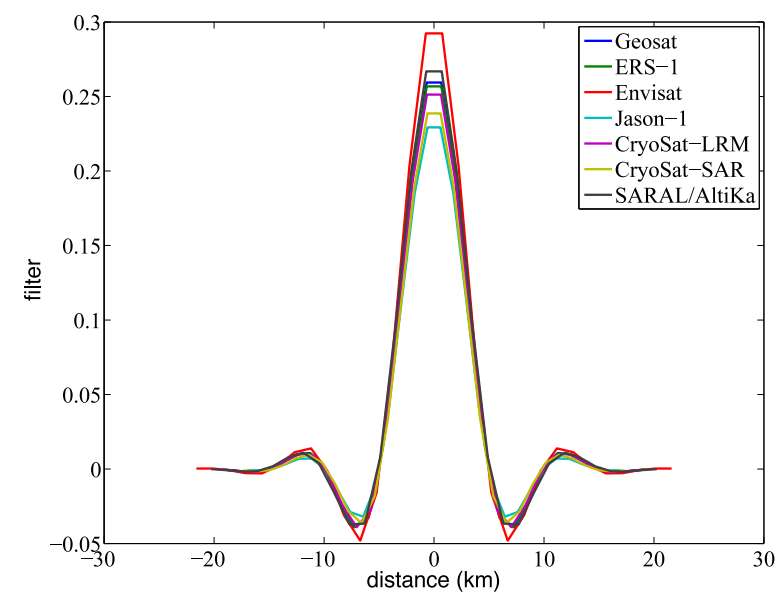

Figure.6 Low-pass filters used for along-track slopes of multi-satellite altimeters

After the above steps, along-track filtered sea surface height gradients data are obtained

for multi-satellite altimeters. Considering the effect of sea surface topography and geoid height, DOT2008A and EGM2008 model are selected respectively to interpolate and subtract from along-track $5 \mathrm{~Hz}$ observations. Then along-track residual vertical deflections are calculated according to velocity formulas at ground track (Sandwell and Smith, 1997). The relationship between along-track residual vertical deflections and 2-dimensional components of residual vertical deflections can be established as equations at each grid point with $1^{\prime} \times 1{ }^{\prime}$ resolution. Consequently, the north and east components of residual vertical deflection are calculated using biharmonic splines with a tension parameter of 0.25 (Wessel and Bercovici, 1998), and then the residual gravity anomaly values shown in Figure 7 on the basis of Laplace Equation and the Fast Fourier Transform (FFT) algorithm. A third low-pass filter having a 0.5 gain at $16 \mathrm{~km}$ is applied during this transformation. At last, the gravity anomaly values of EGM2008 model should be restored. We finally construct the $1^{\prime} \times 1^{\prime}$ marine gravity field model over Southeastern China Seas (Figure 8). 


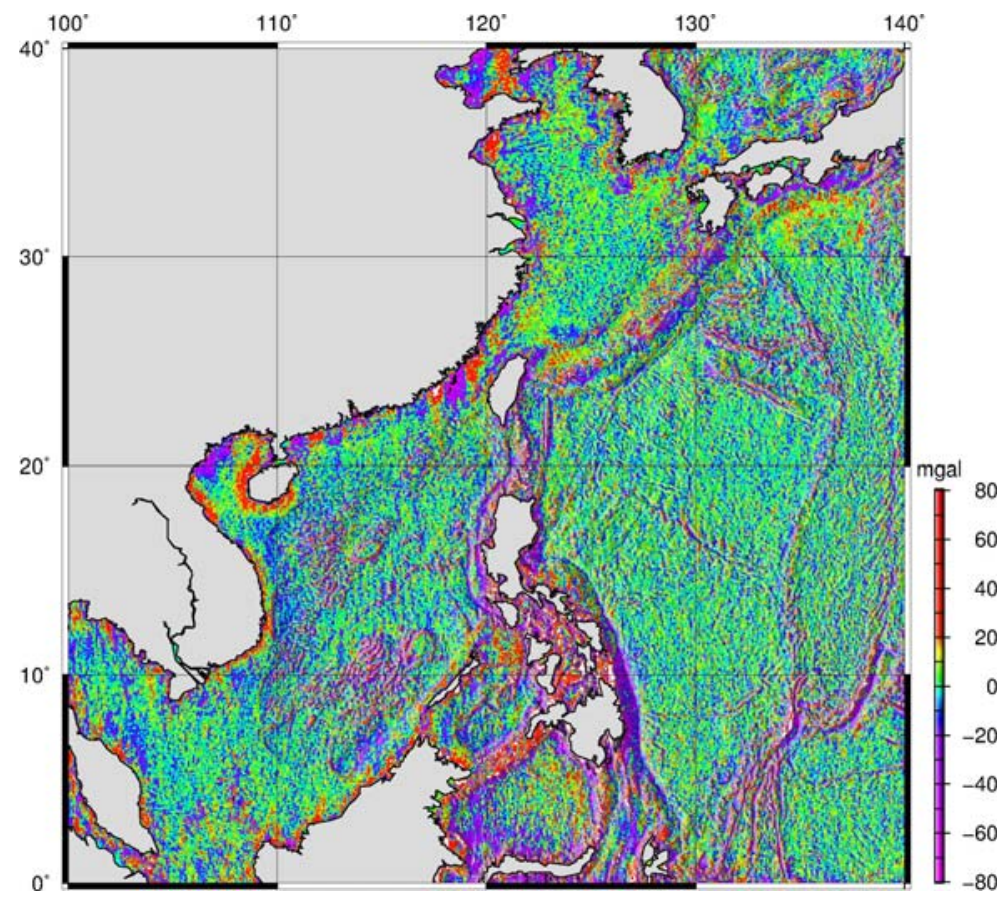

Figure.7 Residual gravity anomaly in the research area

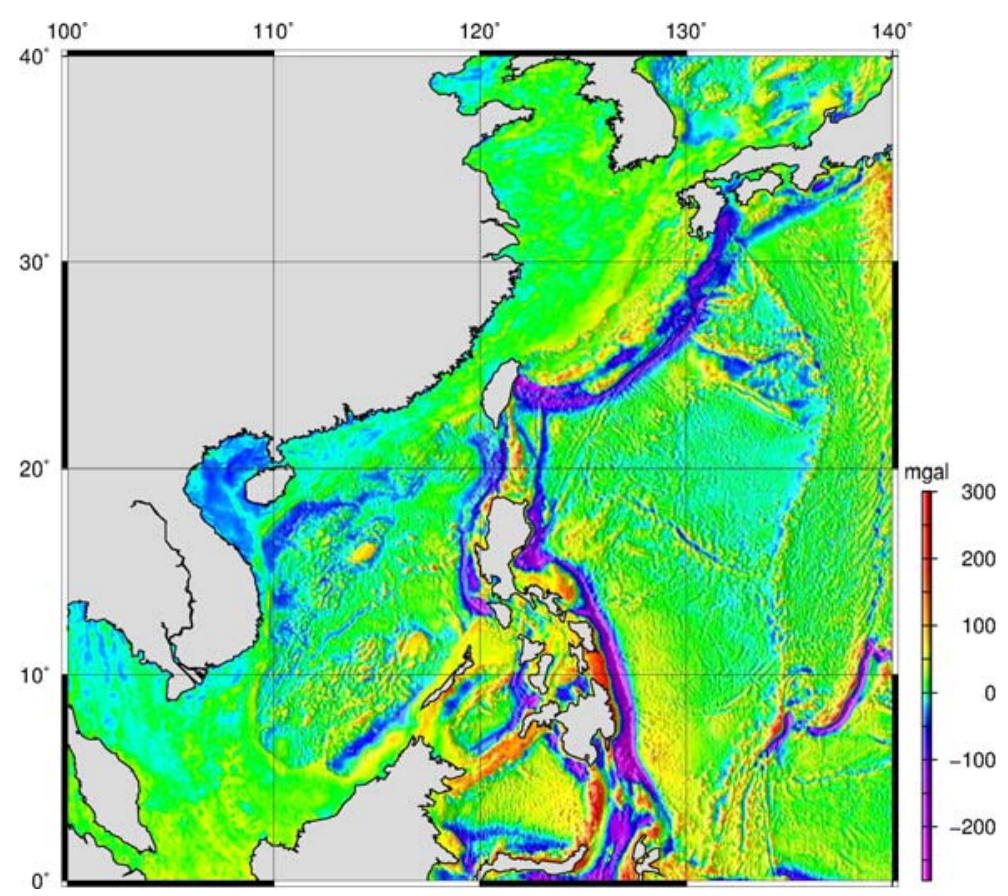

Figure.8 Marine gravity field in the research area

The resulting gravity anomaly grid is evaluated using two techniques. First, we examine

298 the root mean square (RMS) misfit between the result and authoritative global marine gravity 
with gravity anomalies collected by ships. This comparison provides a more independent assessment of data accuracy but is limited to certain areas in which the high-quality shipboard data are available.

The statistical results with global models such as DTU10, DTU13, V23.1 and EGM2008 are provided in Table 7. The discrepancies between the new result and other 4 models are relatively small and the RMS values are within the range of $1.8 \sim 3.9 \mathrm{mGal}$. Among them, the new result gets better accordance with V23.1 model due to the similar method for constructing marine gravity field model from along-track vertical deflections. Besides, the DTU series models agree better with EGM2008 model because of the data intersection with DNSC model while constructing EGM2008 model. Benefiting from the new-added altimeter data such as SARAL/AltiKa, the new result gets a better accuracy if we recognize DTU10, DTU13 and EGM2008 models as standard reference.

\begin{tabular}{ccccc}
\multicolumn{4}{c}{ Table.7 Validation information of inversed result with published gravity models Unit: mGal } \\
\hline Model description & Minimum & Maximum & Mean & RMS \\
\hline New result VS DTU10 & -113.823 & 114.001 & -0.037 & 3.676 \\
New result VS DTU13 & -113.623 & 108.358 & -0.029 & 3.553 \\
New result VS V23.1 & -147.000 & 252.399 & -0.044 & 1.869 \\
New result VS EGM2008 & -106.862 & 108.198 & -0.024 & 3.901 \\
V23.1 VS DTU10 & -240.380 & 128.644 & 0.026 & 4.030 \\
V23.1 VS DTU13 & -186.643 & 127.894 & 0.023 & 3.811 \\
V23.1 VS EGM2008 & -178.061 & 124.937 & 0.028 & 4.144 \\
DTU13 VS DTU10 & -90.598 & 101.300 & 0.003 & 3.134 \\
DTU13 VS EGM2008 & -38.428 & 53.118 & -0.005 & 1.807 \\
DTU10 VS EGM2008 & -107.151 & 94.952 & 0.002 & 2.746 \\
\hline
\end{tabular}

Moreover, the US National Geophysical Data Center (NGDC) provides globally distributed shipboard data and 117 tracks among them locate in the research area as shown in Figure 9. We firstly computed the statistical information for these shipboard data cruise by cruise with respect to EGM2008 model and provided these preliminary evaluations in Table 8. Taking cruise 01010260 (28392 observations) and 67010136 (24462 observations) for instance, the mean values of discrepancies are $19.03 \mathrm{mGal}$ and $-12.88 \mathrm{mGal}$ respectively while the RMS of discrepancies are $8.08 \mathrm{mGal}$ and $5.6 \mathrm{mGal}$ respectively. The verification with respect to the two cruises without considering the system bias will obtain inappropriate results of mean value $(4.28 \mathrm{mGal})$ and RMS value $(17.40 \mathrm{mGal})$. If we adapt a further step to 
322 eliminate the system bias for the two cruises, the corresponding mean value and RMS are

323 respectively $0.0001 \mathrm{mGal}$ and $7.04 \mathrm{mGal}$, which are more reasonable. Meanwhile, these

324 ship-measured data inevitably contain certain number of gross error data limited to various

325 measuring conditions.

Table. 8 Validation information of shipboard data with respect to EGM2008 model for each cruise Unit: mGal

\begin{tabular}{|c|c|c|c|c|c|c|c|c|c|c|c|}
\hline & Cruise & Mean & RMS & & Cruise & Mean & RMS & & Cruise & Mean & RMS \\
\hline 1 & 01010258 & 7.90 & 8.94 & 2 & 01010259 & 21.11 & 7.07 & 3 & 01010260 & 19.03 & 8.08 \\
\hline 4 & 02010055 & -3.41 & 2.99 & 5 & 02010079 & -4.13 & 3.73 & 6 & 03010016 & -2.50 & 10.03 \\
\hline 7 & 06780070 & -1.88 & 8.11 & 8 & 08020049 & -5.93 & 12.72 & 9 & 08020071 & -3.58 & 6.29 \\
\hline 10 & 08020072 & -4.04 & 11.97 & 11 & 15020205 & -2.09 & 4.55 & 12 & 15020206 & -5.42 & 5.83 \\
\hline 13 & 15020207 & -1.39 & 3.76 & 14 & 15040215 & 0.22 & 5.80 & 15 & 16010004 & 9.05 & 11.41 \\
\hline 16 & 16010007 & -5.64 & 6.27 & 17 & 29020003 & 0.13 & 9.49 & 18 & 29040003 & -5.48 & 9.33 \\
\hline 19 & 29044004 & -7.82 & 24.93 & 20 & 29040006 & -4.80 & 7.07 & 21 & 29040007 & -15.24 & 15.31 \\
\hline 22 & 29040008 & 13.41 & 9.62 & 23 & 29040009 & -18.79 & 5.51 & 24 & 29040010 & -17.48 & 4.07 \\
\hline 25 & 29040018 & -12.97 & 3.11 & 26 & 29140001 & 4.57 & 15.09 & 27 & 67010135 & 352.77 & 38.09 \\
\hline 28 & 67010136 & -12.88 & 5.60 & 29 & 67010137 & -0.05 & 7.67 & 30 & 67010138 & 1.87 & 8.55 \\
\hline 31 & 67010139 & 199.44 & 7.81 & 32 & 67010140 & -1.04 & 7.15 & 33 & 67010141 & -1.69 & 6.52 \\
\hline 34 & 67010142 & -5.28 & 12.88 & 35 & 67010143 & 16.17 & 3.54 & 36 & 67010145 & 3.26 & 7.06 \\
\hline 37 & 67010146 & -2.90 & 6.61 & 38 & 67010147 & -0.97 & 6.48 & 39 & 77030001 & -8.12 & 14.63 \\
\hline 40 & 77030003 & -12.41 & 13.32 & 41 & 77990001 & 4.55 & 15.10 & 42 & J1010001 & -26.85 & 23.53 \\
\hline 43 & J1010036 & -4.95 & 7.46 & 44 & J1010037 & 1.79 & 8.16 & 45 & J1010038 & -1.03 & 6.89 \\
\hline 46 & J1010039 & -0.09 & 6.88 & 47 & J1020001 & -0.94 & 8.99 & 48 & J1020002 & 2.01 & 7.00 \\
\hline 49 & J1020003 & 2.24 & 6.13 & 50 & J1020006 & 7.87 & 7.50 & 51 & J1020007 & 2.90 & 6.08 \\
\hline 52 & J1020008 & 4.97 & 7.45 & 53 & J1020009 & -4.07 & 7.30 & 54 & J1020010 & 3.98 & 8.16 \\
\hline 55 & J1020011 & -5.96 & 7.76 & 56 & J1020012 & -2.92 & 5.64 & 57 & J1020016 & -0.19 & 6.67 \\
\hline 58 & J1020021 & -4.85 & 7.46 & 59 & J1020022 & -5.27 & 5.88 & 60 & J1020024 & -1.96 & 6.91 \\
\hline 61 & J1020026 & 6.57 & 7.07 & 62 & J1020027 & 5.18 & 6.68 & 63 & J1020029 & -2.61 & 8.40 \\
\hline 64 & $\mathrm{~J} 1020030$ & -5.27 & 8.63 & 65 & J1020031 & -2.96 & 10.61 & 66 & J1020032 & -2.56 & 8.42 \\
\hline 67 & J1020033 & -6.18 & 5.87 & 68 & J1020038 & 0.87 & 5.46 & 69 & J1030002 & -2.13 & 9.98 \\
\hline 70 & J1030007 & -11.90 & 13.24 & 71 & $\mathrm{~J} 1030008$ & -5.95 & 5.56 & 72 & J1030009 & -3.49 & 7.60 \\
\hline 73 & $\mathrm{~J} 1030010$ & -0.16 & 7.27 & 74 & $\mathrm{~J} 1030024$ & -8.91 & 8.72 & 75 & J1030025 & -4.26 & 5.43 \\
\hline 76 & J1030027 & -2.24 & 5.66 & 77 & $\mathrm{~J} 1030028$ & -1.01 & 7.22 & 78 & J1030030 & -1.27 & 7.41 \\
\hline 79 & J1030031 & -2.25 & 9.38 & 80 & $\mathrm{~J} 1030033$ & -8.63 & 4.81 & 81 & J1030034 & -10.99 & 13.65 \\
\hline 82 & J2010002 & 0.04 & 15.07 & 83 & J2010003 & -1.31 & 15.85 & 84 & J2010004 & 1.21 & 13.15 \\
\hline 85 & J2010005 & -0.87 & 9.95 & 86 & J2010008 & -5.35 & 41.68 & 87 & J2010009 & -6.34 & 10.88 \\
\hline 88 & J2010010 & -0.19 & 11.88 & 89 & J2010011 & 2.83 & 23.10 & 90 & J2010012 & 1.82 & 10.26 \\
\hline 91 & J2010013 & -2.20 & 35.39 & 92 & J2010014 & -0.98 & 9.03 & 93 & J2010015 & 2.56 & 9.31 \\
\hline 94 & J2010027 & 0.15 & 6.00 & 95 & J2010028 & 0.29 & 4.53 & 96 & J2010029 & 0.81 & 5.54 \\
\hline 97 & J2010030 & -0.08 & 3.40 & 98 & J2010031 & 0.61 & 5.29 & 99 & J2010032 & 0.55 & 6.24 \\
\hline 100 & J2010033 & -1.08 & 5.41 & 101 & J2010034 & -0.35 & 5.78 & 102 & J2010035 & -0.65 & 5.43 \\
\hline 103 & J2010036 & 1.10 & 5.65 & 104 & J2010037 & -0.18 & 5.46 & 105 & J2010038 & 0.23 & 6.37 \\
\hline 106 & J2010039 & 0.46 & 4.03 & 107 & $\mathrm{Ja} 010001$ & -5.11 & 17.66 & 108 & $\mathrm{Ja} 010004$ & 12.24 & 22.57 \\
\hline 109 & $\mathrm{Ja} 010005$ & -0.78 & 10.08 & 110 & $\mathrm{Ja} 010006$ & -7.30 & 11.67 & 111 & $\mathrm{Ja} 010008$ & -1.53 & 8.51 \\
\hline 112 & Ja010009 & 0.64 & 73.63 & 113 & $\mathrm{Ja} 010013$ & -5.60 & 12.58 & 114 & $\mathrm{Ja} 010019$ & -8.81 & 5.89 \\
\hline
\end{tabular}




\begin{tabular}{llllllllllll}
\hline 115 & $\mathrm{Ja} 010025$ & 3.80 & 3.40 & 116 & $\mathrm{Ja} 010026$ & -11.39 & 6.37 & 117 & $\mathrm{Ja} 010029$ & 0.69 & 5.45 \\
\hline
\end{tabular}

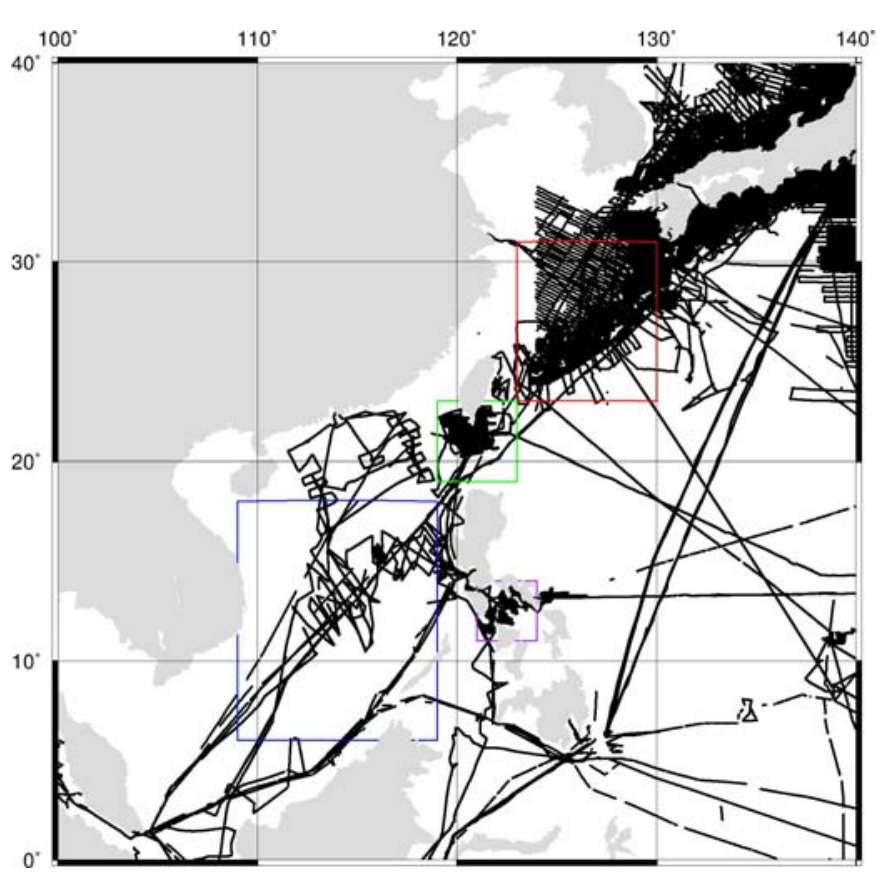

Figure.9 Trajectory of NGDC ship-measured gravity data in the research area

Table.9 Validation information of inversed result with NGDC shipboard gravity data Unit: mGal

\begin{tabular}{|c|c|c|c|c|c|}
\hline $\begin{array}{c}\text { Shipboard data } \\
\text { description }\end{array}$ & Validate data & Minimum & Maximum & Mean & RMS \\
\hline \multirow{5}{*}{$\begin{array}{c}\text { ALL } \\
(3.17 \%)\end{array}$} & New result VS Shipboard & -40.078 & 71.381 & -0.097 & 6.043 \\
\hline & EGM2008 VS Shipboard & -19.999 & 19.999 & 0.131 & 6.273 \\
\hline & DTU10 VS Shipboard & -26.886 & 27.643 & 0.140 & 6.247 \\
\hline & DTU13 VS Shipboard & -31.972 & 33.281 & 0.139 & 5.969 \\
\hline & V23.1 VS Shipboard & -42.594 & 83.899 & -0.122 & 6.108 \\
\hline \multirow{5}{*}{$\begin{array}{c}\text { Coastal area } \\
(<100 \mathrm{~m})\end{array}$} & New result VS Shipboard & -39.969 & 47.336 & 1.432 & 7.678 \\
\hline & EGM2008 VS Shipboard & -19.997 & 19.977 & 1.662 & 7.108 \\
\hline & DTU10 VS Shipboard & -23.881 & 21.706 & 1.651 & 7.211 \\
\hline & DTU13 VS Shipboard & -26.673 & 28.141 & 1.870 & 7.279 \\
\hline & V23.1 VS Shipboard & -35.391 & 58.192 & 1.293 & 7.696 \\
\hline \multirow{5}{*}{$\begin{array}{l}\text { Open sea } \\
(>3000 \mathrm{~m})\end{array}$} & New result VS Shipboard & -32.055 & 25.172 & 0.240 & 5.445 \\
\hline & EGM2008 VS Shipboard & -19.995 & 19.999 & 0.445 & 5.642 \\
\hline & DTU10 VS Shipboard & -23.676 & 22.073 & 0.466 & 5.596 \\
\hline & DTU13 VS Shipboard & -28.444 & 25.258 & 0.390 & 5.534 \\
\hline & V23.1 VS Shipboard & -32.303 & 25.201 & 0.262 & 5.432 \\
\hline
\end{tabular}

Consequently these shipboard gravity data need extra procedures to eliminate system bias

331 and delete gross error data according to the preliminary evaluations with respect to EGM2008, 332 while the threshold of $20 \mathrm{mGal}$ leads to a total proportion of $3.17 \%$ for deleted data. Then 333 these shipboard data were used for a more reasonable verification. Besides, we also counted 334 the statistical results for shipboard data of which water depths are either larger than $3000 \mathrm{~m}$ or 
smaller than $100 \mathrm{~m}$ on the basis of values interpolated from ETOPO1 model. The verifications

with respect to ship-measured gravity data are all provided in Table 9, which demonstrate that

337 the new result reaches the accuracy level of DTU13 and V23.1, also is superior to DTU10 and

338 EGM2008. In addition, the accuracy of calculated result over open seas is almost $2 \mathrm{mGal}$

339 better than the result over coastal area with a shallow water depth.

340 Considering the effect of complicated submarine topography and sea surface topography,

341 we selected typical regions over the research area for a further comparison. The selected 4

342 rectangular areas are South China Sea Basin (blue rectangular in Figure 9), sea areas off

343 Taiwan's southern coast (green rectangular in Figure 9), Okinawa through and its adjacent

344 area (red rectangular in Figure 9), and sea areas around Philippine Islands (purple rectangular

345 in Figure 9), respectively. As is shown in Table 10, the verification between shipboard

346 profiles and gravity models demonstrates the improvement in accuracy due to waveform 347 retracking and updated correction of ocean tide, especially obvious over South China Sea

348 Basin and sea areas around Philippine Islands. Besides, the supplement of latest CryoSat-2 349 and SARAL/AltiKa data also brings better accuracy for constructing marine field model in 350 comparison with V23.1 model.

Table.10 Validation information with NGDC shipboard gravity data over typical areas Unit: mGal

\begin{tabular}{cccccc}
\hline Typical area & Validate data description & Minimum & Maximum & Mean & RMS \\
\hline \multirow{5}{*}{ South China } & New result VS Shipboard & -27.984 & 27.208 & -0.938 & 5.986 \\
Sea Basin & EGM2008 VS Shipboard & -20.362 & 20.030 & -1.060 & 6.324 \\
& DTU10 VS Shipboard & -21.242 & 20.428 & -1.045 & 6.403 \\
& DTU13 VS Shipboard & -28.363 & 23.838 & -1.152 & 6.058 \\
& V23.1 VS Shipboard & -3.123 & 29.940 & -1.025 & 6.223 \\
\hline \multirow{2}{*}{ Off Taiwan's } & New result VS Shipboard & -26.338 & 34.126 & 0.187 & 5.217 \\
southern coast & EGM2008 VS Shipboard & -20.122 & $20 / 159$ & 0.377 & 5.546 \\
& DTU10 VS Shipboard & -21.301 & 22.399 & 0.349 & 5.478 \\
& DTU13 VS Shipboard & -24.903 & 32.348 & 0.510 & 5.176 \\
\hline \multirow{2}{*}{ Okinawa } & V23.1 VS Shipboard & -36.272 & 29.497 & 0.074 & 6.120 \\
\hline through and its & New result VS Shipboard & -31.773 & 40.089 & -0.670 & 5.647 \\
adjacent area & EGM2008 VS Shipboard & -20.031 & 19.997 & 0.040 & 5.610 \\
& DTU10 VS Shipboard & -21.991 & 22.281 & -0.029 & 5.672 \\
& DTU13 VS Shipboard & -28.554 & 28.180 & -0.199 & 5.453 \\
\hline Around & V23.1 VS Shipboard & -36.029 & 42.795 & -0.682 & 6.141 \\
\hline Philippine & New result VS Shipboard & -42.073 & 35.654 & -0.056 & 8.279 \\
& EGM2008 VS Shipboard & -20.395 & 20.112 & -1.834 & 9.216 \\
& DTU10 VS Shipboard & -27.713 & 26.043 & -1.802 & 9.122 \\
\hline
\end{tabular}




\section{Conclusion}

Satellite altimetry provides the most comprehensive images of marine gravity field with accuracies approaching typical shipboard gravity data. Based on multi-satellite altimeter data including the supplement of SARAL/AltiKa, Jason-1 GM and CryoSat-2, we discussed the detailed procedures of constructing regional gravity anomaly grids derived from along-track waveforms. Our analysis uses three approaches to reduce the error in the satellite-derived results. First, we compared 6 retracking methods with Jason-1 GM sample data over the research area and selected the two-step WLS retracker with minimum along-track slope error to process raw waveforms of various altimetry missions. Second, we used a resampling procedure combined with a designed low-pass filter to obtain uniformly along-track $5 \mathrm{~Hz}$ data with enhanced sampling rate and measuring accuracy. Third we compared 5 ocean tide models with tide gauge data and selected WHU12 model to update corrections. We finally calculated the 1' $\times 1$ ' marine gravity field model over the Southeastern China Seas using EGM2008 model in the remove/restore procedure.

Two approaches are used to evaluate the accuracy of the new gravity model: published global gravity models and NGDC shipboard gravity data, respectively. Kinds of verifications show that accuracy of the new result reaches the level of DTU13 and V23.1. Meanwhile, the new gravity result is slightly better than DTU10 and EGM2008 model. In the selected typical areas with complicated seafloor topography and sea surface topography, the new result is also superior to V23.1 model. Generally speaking, the new result significantly improve the accuracy and resolution of regional gravity models over the Southeastern China Seas due to waveform retracking, low-pass filtering, correction updating and data supplement of new satellite missions. 
Acknowledgements - The multi-satellite altimeter data were provided by CNES and European

Space Agency. Zhang was supported by 973 Project of China (No.2013CB73301, No.2013CB73302),

National Natural Science Foundation of China (No.41210006, No.41304003) and the project of Key

Laboratory of Geospace Environment and Geodesy, Ministry of Education, China (No.20150209).

Sandwell was supported by the National Geospatial-Intelligence Agency (HM0177-13-1-0008) and

\section{Reference}

Amarouche L, Thibaut P, Zanife O Z, et al., 2004. Improving the Jason-1 ground retracking to better account for attitude effects. Marine Geodesy, 27: 171-197.

Andersen O B, Knudsen P, 1998. Global marine gravity field from the ERS-1 and Geosat geodetic mission altimetry. Journal of Geophysical Research, 103(C4): 8129-8137.

Andersen O B, Knudsen P, Kenyon S, et al., 2014. Global and Arctic Marine Gravity Field From Recent Satellite Altimetry (DTU13). 76th EAGE Conference and Exhibition, 10.3997/2214-4609.20140897.

Brown G S, 1977. The average impulse response of a rough surface and its applications. IEEE Transactions on Antennas and Propagation, 25(1): 67-74.

Challenor P G, Scrokosz M A, 1989. The extraction of geophysical parameters from radar altimeter return from a non-linear sea surface. in Mathematics in remote sensing. Clarandon Press, Oxford, 257-268.

Chang X T, Li J C, Guo J Y, et al., 2006. A multi-leading edge and multi-threshold waveform retracker. Chinese J. Geophys. (in Chinese), 49(6): 1629-1634.

Chelton D B, Ries J C, Haines, Fu L L, Callahan, P S, 2001. Satellite altimetry, in Satellite Altimetry and Earth Sciences, eds. Fu, L.-L. \& Cazenave, A., Academic Press. 1-131.

Cheng Y, Andersen A B, 2011. Multimission empirical ocean tide modeling for shallow waters and polar seas. Journal of Geophysical Research, 116, C11001, doi:10.1029/2011JC007172.

Davis C H. 1993. A surface and volume scattering retracking algorithm for ice sheet satellite altimetry. IEEE Transactions on Geoscience and Remote Sensing, 31(4): 811-818.

Garcia E S, Sandwell D T, Smith W H F. 2014. Retracking CryoSat-2, Envisat and Jason-1 radar altimetry waveforms for improved gravity field recovery. Geophysical Journal International, 196(3):1402-1422.

Gommenginger C, Thibaut P, Fenoglio-Marc L, et al., 2011. Retracking altimeter waveforms near the coasts. in Coastal altimetry, eds. Vingnudelli, S., et al., DOI:10.1007/978-3-642-12796-0_4, ( ) Springer-Verlag Berlin Heidelberg.

Guo J Y, Gao Y G, Hwang C W, et al., 2010. A multi-subwaveform parametric retracker of the radar satellite altimetric waveform and recovery of gravity anomalies over coastal oceans. Science China Earth Sciences, 53(4): 610-616.

Haxby W F, Karner G D, Labrecque J L, et al., 1983. Digital images of combined oceanic and continental data sets and their use in tectonic studies. EOS, Transactions, American Geophysical Union. 64: 995-1004.

HSU Hou-Tse, Wang Hai-Ying, Lu Yang, Wang Guang-Yun. Geoid undulations and gravity anomalies from T/P and ERS-1 altimeter data in the China sea and vicinity. Chinese J. Geophys. (in Chinese), 42(4): 465-471. 1999. 
Huang Mo-tao, Zhai Guo-jun, Guan Zheng, et al., 2001. On the recovery of gravity anomalies from altimter data. Acta Geodaetica et Cartographica Sinica (in Chinese), 30(2): 179-184.

Huang Mo-tao, Zhai Guo-jun, Ouyang Yong-zhong, et al., 2006. Recovery of marine gravity field using integrated data from multi-satellite missions. Science of Surveying and Mapping(in Chinese), 31(6): 37-39.

Hwang C. 1998. Inverse Vening Meinesz formula and deflection-geoid formula: applications to the predictions of gravity and geoid over the South China Sea. Journal of Geodesy, 72(5): 304-312.

Hwang C, Guo J Y, Deng X, et al., 2006. Coastal gravity anomalies from retracked Geosat GM altimetry: improvement, limitation and the role of airborne gravity data. Journal of Geodesy, 80(4): 204-216.

Li Jian-cheng, Ning Jin-sheng, Chen Jun-yong, Chao Ding-bo. 2001. Determining of gravity anomalies over the south China sea by combination of TOPEX/Poseidon, ERS2 and Geosat altimeter data. Acta Geodaetica et Cartographica Sinica (in Chinese), 30(3): 197-202.

Lyard F, Lefèvre F, Letellier T, et al., 2006. Modelling the global ocean tides: modern insights from FES2004. Ocean Dynamics, 56: 394-415.

Marks K M, Smith W H F, 2016. Detecting small seamounts in AltiKa repeat cycle data. Mar. Geophys. Res., DOI 10.1007/s11001-016-9293-0.

Martin T V, Zwally H J, Brenner A C, et al., 1983. Analysis and retracking of continental ice sheet radar altimeter waveforms. Journal of Geophysical Research, 88(C3): 1608-1616.

Olgiati A, Balmino G, Sarrailh M, et al., 1995. Gravity anomalies from satellite altimetry: comparison between computation via geoid heights and via deflections of the vertical. Bulletin géodésique, 69(4): 252-260.

Raney, R K, Phalippou, L, 2011. The future of coastal altimetry. in Coastal altimetry, eds. Vingnudelli, S., et al., 535-560. DOI: 10.1007/978-3-642-12796-0_20, @ Springer-Verlag Berlin Heidelberg.

Rapp R H, 1979. Geos 3 data processing for the recovery of geoid undulations and gravity anomalies. Journal of Geophysical Research, 84(B8): 3784-3792.

Sandwell D T, 1984. Along-track deflection of the vertical from Seasat: GEBCO overlays. US Department of Commerce, National Oceanic and Atmospheric Administration, National Ocean Service, National Geodetic Survey, Charting and Geodetic Services.

Sandwell D T, Garcia E, Soofi K, et al., 2013. Toward 1-mGal accuracy in global marine gravity from CryoSat-2, Envisat, and Jason-1. The Leading Edge, 32(8): 892-899.

Sandwell D T, Müller R D, Smith W H F, et al., 2014. New global marine gravity model from CryoSat-2 and Jason-1 reveals buried tectonic structure. Science, 346(6205): 65-67.

Sandwell D T, Smith W H F, 1997. Marine gravity anomaly from Geosat and ERS1 satellite altimetry. Journal of Geophysical Research, 102(B5): 10039 -10054.

Sandwell D T, Smith W H F, 2005. Retracking ERS-1 altimeter waveforms for optimal gravity field recovery. Geophysical Journal International, 163(1): 79-89.

Sandwell D T, Smith W H F, 2009. Global marine gravity from retracked Geosat and ERS-1 altimetry: Ridge segmentation versus spreading rate. Journal of Geophysical Research, 114, B014411, doi:10.1029/2008JB 006008 .

Sarrailh M, Balmino G, Doublet D. 1997. The Arctic and Antarctic Oceans Gravity Field from ERS1 Altimetric Data. International Association of Geodesy Symposia, 117: 437-444.

Savcenko R, Bosch W, 2008. EOT08a - empirical ocean tide model from multi-mission satellite altimetry. München: Deutsches Geodätisches Forschungsinstitut.

Schrama E J O, Ray R D, 1994. A preliminary tidal analysis of TOPEX/POSEIDON altimetry. Journal of Geophysical Research, 99: 24799-24808.

Smith, W H F. 2015. Resolution of Seamount Geoid Anomalies Achieved by the SARAL/AltiKa and Envisat RA2 
Satellite Radar Altimeters. Marine Geodesy, 38:sup1, 644-671, DOI: 10.1080/01490419.2015.1014950.

Stammer D, Ray R D, Andersen O B, et al., 2014. Accuracy assessment of global barotropic ocean tide models. Reviews of Geophysics, 52(3): 243-282.

Wessel, P., Bercovici D. 1998. Interpolation with splines in tension: A Green's function approach. Math. Geol., 30(1): 77 - 93, doi:10.1023/A:1021713421882.

Wingham D J, Rapley C G, Griffiths H., 1986. New techniques in satellite altimeter tracking systems. ESA Proceedings of the 1986 International Geoscience and Remote Sensing Symposium(IGARSS'86) on Remote Sensing: Today's Solutions for Tomorrow's Information Needs.

Yang Yuan-de, E Dong-chen, Hwang Cheinway, Wang Hai-hong. 2008. Chinese coastal gravity anomalies from waveform retracked Geosat/GM altimetry. Geomatics and Information Science of Wuhan University (in Chinese), 33(12): 1288-1291.

Zhang S, Sandwell D T, 2016. Retracking of SARAL/AltiKa radar altimetry waveforms for optimal gravity field recovery. Marine Geodesy. DOI: 10.1080/01490419.2016.1265032. 